\title{
Evaluación intersubjetiva: objetividad y alcances
}

\author{
Intersubjectiveevaluation: objectivity and extents \\ Roberto Beltrán Neira ${ }^{1 a}$, María Cristina Ikeda-Artacho ${ }^{1 b}$
}

\section{Rol de la evaluación}

Hoy en día reconocemos a la evaluación como una parte fundamental para el logro y la verificación de los aprendizajes; por ello, el binomio enseñanza-aprendizaje debe completarse para convertirse en el trípode: Enseñanza-Aprendizaje-Evaluación (1).

Antes de la vigencia de las llamadas pruebas objetivas, los exámenes escritos eran conceptuales y poco aplicativos; no faltaba en muchos de ellos la famosa pregunta que evocaba a la memoria: "Liste usted las partes de...", las respuestas a preguntas de desarrollo obligaban a los profesores a destinar grandes tiempos para la lectura de las respuestas y corrección de exámenes.

La prueba objetiva fue el gran invento que facilitó la corrección de las evaluaciones, que inclusive podía ser hecha por un profesor auxiliar.

\section{Lo objetivo es insuficiente}

Sin embargo, como suele ocurrir, “lo que se gana por un lado se pierde por el otro”. Los alumnos estudiaban para responder preguntas objetivas y no para aprender. Muchos profesores se confiaron en el aprendizaje memorístico y en la nota cuantitativa para aprobar a los alumnos. Los aspectos cualitativos del saber quedaron postergados. Los exámenes orales desaparecieron.

Los múltiples aspectos del saber hicieron del aprendizaje un mosaico de piezas que no conformaban una imagen completa. Las evaluaciones objetivas no proporcionaban la suficiente objetividad para verificar el logro de los aprendizajes y retroalimentar con pertinencia al alumno.

\section{La observación}

Una excelente técnica para evaluar el desempeño idóneo de las competencias es la observación directa, ya sea en un escenario real o simulado, según su viabilidad y pertinencia.

El resultado de la evaluación mediante la técnica de observación directa aumenta su validez y precisión cuan-

\footnotetext{
${ }^{1}$ Facultad de Estomatología Roberto Beltrán, Universidad Peruana Cayetano Heredia. Lima, Perú.

a Profesor Emérito, Epónimo y Fundador de la Facultad de Estomatología de la Universidad Peruana Cayetano Heredia.

${ }^{\mathrm{b}}$ Profesora Principal
} 
do la apreciación del desempeño es realizada por más de un evaluador, es decir, llevando a cabo una evaluación ponderada. La posibilidad de que exista más de un evaluador compensa el riesgo de subjetividad que la apreciación personal e individual pueda acarrear.

Así planteada, la observación de un desempeño (conducta objetiva) nutre la apreciación de dos o más evaluadores, a partir de la cual los mismos ponderan su evaluación individual y son capaces de emitir un juicio de valor conjunto, considerando que:

- En cualquier espacio de interacción profesor-alumno, el profesor es capaz de reconocer y diferenciar - luego de cierto tiempo de observación - alumnos "excelentes", "buenos", “malos” e "irrecuperables”, en función de los desempeños que realizan.

- Este conocimiento también es compartido por los mismos alumnos entre sí.

- La apreciación es de ordinario acertada.

\section{Apreciación subjetiva}

En consecuencia, cabría esta forma "intersubjetiva” de apreciar el rendimiento del alumno más allá del resultado de los exámenes. Se trataría de una forma supracognitiva de percibir el rendimiento del estudiante. Probablemente, una apreciación subjetiva capaz de compendiar una serie de indicadores. Un factor vinculado a la calidad de la apreciación subjetiva probablemente sea el nivel de expertise del evaluador. Consideramos que la capacidad de conducir con éxito, justicia y equidad una apreciación subjetiva exige un nivel mínimo de experiencia, sustentando principalmente en la ejecución previa de los desempeños evaluados.

\section{Principales características de la enseñan- za-aprendizaje-evaluación tradicional. \\ Los dominios del aprendizaje}

Los procesos de enseñanza-aprendizaje-evaluación tradicionalmente se han caracterizado por:

Las lecciones eran mayormente expositivas: los profesores se tomaban todo el tiempo disponible, apenas cabía espacio para las preguntas del alumno. La discusión crítica estaba desterrada.

Se desconocía la importancia de la discusión grupal como medio de profundización y retención del aprendizaje.

Los aprendizajes puramente cognitivos no consi- deraban los aspectos afectivos, psicomotores y volitivos de la conducta.

Las disciplinas, encerradas en sí mismas, ignoraban las relaciones interdisciplinarias y holísticas del saber.

Los profesores basaban su enseñanza en los contenidos de los libros de texto, con escaso aporte personal.

Año tras año las clases se repetían sin cambios.

El instructor clínico se limitaba a calificar las etapas de los procedimientos con poca interrelación profesor-alumno en apoyo del aprendizaje.

\section{En cambio...}

La observación continua de la conducta del alumno durante la práctica clínica minimiza la necesidad de exámenes escritos que imponen una carga más, tanto a los alumnos como a los profesores.

La presencia permanente de los profesores en las prácticas clínicas aumenta su disponibilidad para absolver consultas de los alumnos y asegurar un adecuado tratamiento del paciente.

\section{Evaluación holística}

En el proceso de enseñanza-aprendizaje-evaluación de la clínica odontológica, la función evaluadora holística llevaría al profesor a complementar e integrar su trabajo frente al alumno y al paciente.

$\mathrm{Su}$ responsabilidad, en último término, consistiría en formarse una opinión integradora sobre las capacidades logradas por el alumno para alcanzar el dominio de los desempeños y el logro de las competencias. Esta sería la evaluación subjetiva personal, que el profesor podría compartir en un momento de evaluación intersubjetiva a cargo de un jurado conformado para la evaluación de cada alumno.

\section{El más calificado}

El profesor clínico adecuadamente entrenado e interesado en el aprendizaje de sus alumnos es la persona más calificada para dar testimonio del dominio alcanzado por el alumno en la ejecución de determinados desempeños, así como capaz de entenderlos como parte de un plan integral de tratamiento.

\section{Momentos de aplicación}

La evaluación intersubjetiva puede aplicarse al término de las grandes unidades del aprendizaje clínico odontológico y al término de la carrera. 
La evaluación intersubjetiva al término de la carrera puede ser realizada por un jurado compuesto por profesores clínicos familiarizados con un determinado alumno y un profesor principal afín al aprendizaje clínico.

\section{Primacía de la evaluación intersubjetiva}

Para enriquecer la evaluación intersubjetiva se puede utilizar el portafolio del alumno, con sus calificaciones cuantitativas. Existen casos límites en los que la evaluación intersubjetiva del jurado sería definitoria.

La evaluación intersubjetiva culmina con una entrevista personal para la entrega de resultados al graduando, que debe operacionalizarse mediante una comunicación oral amigable entre futuros colegas.

\section{Calificación cualitativa}

La evaluación subjetiva del desempeño ofrece dos opciones de calificativo, de carácter cualitativo:

Demostró las competencias.

Aún no demostró las competencias.

En el segundo caso, el jurado debe emitir una prescripción que indique el período adicional que requiere cursar el alumno desaprobado para poder demostrar el desempeño.

\section{Certificación}

La evaluación intersubjetiva es particularmente útil para la certificación de las competencias profesionales al término de la carrera.

\section{Naturaleza de lo subjetivo}

La apreciación subjetiva del profesor es de orden cognitivo-afectivo-intuitivo.

El adecuado uso de guías de observación con indicadores objetivos sirven de base para emitir el juicio de la evaluación, pero de ninguna manera son suficientes para sustituir la calidad supracognitiva de la evaluación intersubjetiva.

La continua relación profesor-alumno garantizaría un adecuado conocimiento del nivel de aprendizaje logrado por el alumno.

\section{Presencia dialogante}

La conversación entre alumnos y profesores debe ser una práctica cotidiana,hecho que favorece el mutuo conocimiento que, a su vez, resulta de gran utilidad para la evaluación intersubjetiva.Para que esto sea posible, es conveniente que el profesorado esté accesible al alumnado en los ambientes universitarios fuera de las horas lectivas y los turnos clínicos. La universidad debe contar con un alto porcentaje de profesores a tiempo completo cumpliendo tareas de enseñanza, investigación y proyección social. Esto forma parte de la vida universitaria, espacio indispensable para el desarrollo de competencias genéricas que demanda la formación holística de los futuros profesionales.

\section{Valor de lo subjetivo}

Terminemos con el mito de que solo lo objetivo tiene valor en la evaluación.

Contribuyamos a aumentar la confianza del profesor en su capacidad para emitir un juicio como evaluador, a partir de una prolongada relación con el alumnado en la actividad clínica odontológica.

Si se opta por la evaluación subjetiva, el alumno desde su ingreso a la Universidad debe ser informado detalladamente sobre las características inherentes a este tipo de evaluación y su equivalencia con las exigencias objetivas de la normativa educativa vigente. Asimismo, se debe explicar que los desempeños y la conducta del alumno en su integridad serán motivo de evaluación y, no solamente, la respuesta a preguntas en los exámenes.

\section{Conclusiones sobre la evaluación intersubjetiva}

Lo subjetivo como dimensión del trabajo cerebral es recuperable para la evaluación y beneficioso para el profesor y el alumno.

Cabe preguntarse, entonces, si un conjunto de opiniones subjetivas se convierten en verdad objetiva cuando alcanzan consenso.

\section{Correspondencia:}

Roberto J. Beltrán Neira

La Conquista 345. El Derby de Monterrico. Surco. Lima 33

Correo electrónico: robertobeltranneira@gmail.com María Cristina Ikeda Artacho

Correo electrónico: cikeda@intramed.net 


\section{REFERENCIAS BIBLIOGRÁFICAS}

1. Ikeda-Artacho MC, Beltrán-Neira RJ. Aprendizaje basado en competencias - ABC. El caso de Odontología. Lima: Universidad Peruana Cayetano Heredia; 2006.

2. Council of Europe. Common European Framework of Reference for Languages: Learning, Teaching, Assessment. Strasbourg: Council of Europe; 2001. p. 171-92.

3. Moreno-Olivos T. Evaluación cualitativa del aprendizaje: Enfoques y tendencias. Revista de la Educación Superior. 2014; 43 (171): 93-118.

4. Zárate J. La Universidad que queremos. Lima: Consejo de Evaluación, Acreditación y Certificación de la Calidad de la Educación Superior Universitaria; 2012.

5. Consejo de Evaluación, Acreditación y Certificación de la Calidad de la Educación Superior Universitaria. Compendio Técnico-Normativo. Criterios y estándares para la certificación profesional en el Perú. Segunda edición. Lima: Consejo de Evaluación, Acreditación y Certificación de la Calidad de la Educación Superior Universitaria; 2012.

6. Beltrán RJ. La educación peruana en el siglo XXI

- La segunda reforma. Lima: Universidad Peruana
Cayetano Heredia; 2011.

7. Beltrán-Neira RJ, Ikeda-Artacho MC, Guerra C. Guía para la preparación de un Módulo para elAprendizaje Clínico Intensivo (MACI). Rev Estomatol Herediana. 2011; 21(1):20-23.

8. Sarmiento V. Una mirada desde la educación superior. Altablero. 2008; 44. Disponible en: http://www.mineducacion.gov.co/1621/article-162368.html

9. Ikeda MC, Huamán L, Beltrán RJ. Agrupamiento según conocimientos previos y ciclo propedéutico. ¿Son herramientas útiles para mejorar el rendimiento académico de los alumnos universitarios? Rev Estomatol Herediana. 2008; 18(1):21-28.

10. Beltrán RJ, Flores M, Ikeda MC. El saber práctico y el aprendizaje de las técnicas en odontología. Rev Estomatol Herediana. 2007; 16(2):139-141.

11. Beltrán RJ, Ikeda MC. Educación en ciencias de la salud - corrientes actuales. Rev Estomatol Herediana. 2006; 16(1):73-74.

12. Ikeda MC, Beltrán RJ. Coordinación académica en la Facultad de Estomatología de la UPCH. Rev Estomatol Herediana. 2005; 15(2):187-189.

Recibido : 2910/2014

Aceptado: 15/04/2015 